\title{
CONTEXTOS SOCIOECOLÓGICOS DO MAU TRATO E DA NEGLIGÊNCIA A CRIANÇAS
}

\author{
Manuela Calheiros e Maria Benedicta Monteiro
}

\begin{abstract}
Resumo O estudo tem por objectivo analisar a importância de um conjunto de variáveis psicossociais na variabilidade das práticas parentais de mau trato e negligência. Teoricamente recorre a investigação baseada em modelos de matriz ecológica (Belsky, 1980; 1993; 1995) e transaccional (Cicchetti e Rizley, 1981; Cicchetti e Lynch, 1993) sobre os determinantes do funcionamento parental. O estudo empírico foi realizado com uma amostra de 379 crianças, com idades entre os 6 e, 15 anos, que frequentam o ensino público na zona da grande Lisboa. Foram preenchidos dois questionários pelos professores. O primeiro avalia as práticas parentais abusivas de mau trato psicológico, mau trato físico e negligência física. O segundo avalia variáveis da criança e da família ao nível do contexto ontogénico, micro, exo e macro. Os resultados obtidos salientam a importância de algumas das variáveis ao nível dos quatro contextos na modulação das diferentes práticas parentais abusivas.'
\end{abstract}

Palavras-chave Contextos ecológicos, contexto social, família, mau trato, negligência, crianças.

\section{Introdução}

O interesse pelos contextos de desenvolvimento do mau trato e negligência a crianças tem estado presente numa variedade de disciplinas ao longo dos últimos anos. Os psicólogos, particularmente os que trabalham no âmbito da psicologia social do desenvolvimento, têm-se debruçado sobre esta área de investigação, na medida em que o seu conhecimento contribui, não só para a compreensão dos processos parentais, como para as implicações dos diferentes estilos parentais no desenvolvimento social das crianças nos seus diferentes sistemas de interacção (Iverson \& Segal, 1992). Por sua vez, os profissionais das áreas aplicadas, tais como a medicina, a educação, a psicologia clínica e a psicologia social, entre outras, manifestam interesse científico pelos contextos do mau trato e da negligência, na medida em que dependem dos resultados de investigação para poderem predizer e implementar estratégias de prevenção e de intervenção ao nível dos indivíduos, das famílias e da comunidade, assim como para poderem contribuir para delinear políticas sociais de segurança social e de saúde. Contudo, e apesar dos avanços feitos nos anos 80 no

Manuela Calhciros e Maria Benedicta Monteiro, Instituto Superior de Ciências do Trabalho c da Empresa, Departamerto de Psicologia Social e das Organizaçס̌es. 
âmbito da investigação e da teorização nos diferentes domínios relativos ao tema e de começarem a aparecer os primeiros modelos multidimensionais - modelo ecológico de Belsky (1980) e modelo transaccional de Cicchetti \& Rizley (1981), cujo focos de investigação são as características dos sistemas em que a criança e a família participam, englobando factores psicológicos, de interacção, sociais e culturais -o esforço de produção empírica derivada desses modelos foi acompanhado por um número significativo de questōes colocadas pelas diferentes disciplinas envolvidas. A escassez de investigação na área da negligência e do mau trato psicológico, a não inclusão de outras áreas de mau trato, que não o abuso físico, a persistência no uso de modelos conceptuais que postulam causas únicas e isoladas num domínio particular — pais, criança ou meio - e a falta de fundamentação teórica heuristicamente generalizada e baseada em resultados empíricos prévios, são as questões mais referidas na literatura, mesmo ainda actualmente (Cicchetti \& Lynch, 1993; Cicchetti \& Toth, 1995; Rossman \& Rosenberg, 1998). Associada a estas questões, e contribuindo também para a dificuldade de revisão e integração da literatura, aparece ainda a inconsistência nas definições e avaliações categoriais do mau trato e da negligência utilizadas em investigação feita pelos técnicos e instituições. As diferentes definições, embora possam ser úteis para alguns fins práticos, têm tornado difícil a constituição das amostras, a avaliação do problema, o estabelecimento de relações consistentes entre variáveis e a generalização e comparação dos resultados.

Face a estas questões, nos anos 90 os investigadores reapropriaram-se da área da definição até aí deixada aos técnicos, com vista à construção de instrumentos de medida que minimizassem os problemas levantados e possibilitassem uma investigação minimamente controlada noutras áreas do mau trato e da negligência, sobretudo nas áreas de risco e respectivas consequências.

Por sua vez, nesta mesma década, as conceptualizações do mau trato, agora que é conhecida a multidimensionalidade do fenómeno, incluem uma rede complexa de agentes causais relacionados, não só com ciclos potencializadores e compensatórios do risco, mas também com os seus efeitos recíprocos.

Além disso, o recurso à articulação entre modelos tem vindo a influenciar uma produção teórica e empírica caracterizada, cada vez mais, pela presença de múltiplas variáveis, construídas a partir dos três sistemas principais de interacção (pais, criança e meio), e pela articulação de diferentes processos e níveis de análise, começando-se a assistir a uma certa convergência e a um número cada vez maior de factores comuns entre os diferentes modelos. Nesta linha de trabalho, esta investigação pretende contribuir para uma melhor compreensão de algumas das questões levantadas, através de um estudo com os seguintes objectivos: 1) proceder à avaliação do mau trato e da negligência familiar numa amostra de crianças inseridas em escolas públicas, utilizando um instrumento de avaliação previamente testado sobre uma amostra mais vasta da população portuguesa, e 2) identificar o impacto de um conjunto de variáveis psicossociais na variabilidade das práticas de mau trato e de negligência familiar. 


\section{Determinantes do mau trato e da negligência}

Partindo do modelo ecológico sobre o desenvolvimento humano de Bronfenbrenner (1979), Belsky (1980; 1993; 1995), numa versão modificada deste modelo, descreve um sistema de níveis interactivos que contribuem para o desenvolvimento de comportamentos abusivos. Incorporando aos "três espaços ecológicos" (micro, macro e exo-sistemas) de Bronfenbrenner (1979), o "contexto histórico da situação", os antecedentes imediatos e as consequências (Burgess, 1978; Tinbergen, 1951, citado em Zigler \& Hall, 1989), o modelo de Belsky propõe quatro níveis interactivos, compreendidos em diferentes esferas de influência: (1) nível de desenvolvimento ontogénico, que diz respeito ao contexto de desenvolvimento psicológicocontribuição dos pais e da criança; (2) o micro-sistema, que envolve o meio imediato da criança-família e as suas interacções; (3) o exo-sistema, que inclui aspectos da comunidade em que as famílias e as crianças vivem; e (4) o macro-sistema, que diz respeito aos determinantes sociais e culturais.

Pela mesma altura, Cicchetti e Rizley (1981), focando o conceito de "factores de risco", utilizam a perspectiva de desenvolvimento transaccional de Sameroff e Chandler (1975) para analisarem as causas do mau trato como expressão duma disfunção subjacente ao sistema pais-criança-meio, através da análise das interacções dinâmicas e contínuas entre a criança, a família e o contexto social. Os autores reconhecem a existência de mecanismos que desencadeiam compensações e tendências de autocorreç̧ão sempre que se detectam desvios num subsistema. Assim, os resultados do desenvolvimento só podem ser vistos tendo em consideraçāo as múltiplas transacções entre forças do meio, características do educador e características da criança, num processo que evolui através de reestruturações regulares, de forma que os acontecimentos e as características passadas podem ser ultrapassados e integrados em novas aquisições.

No entanto, a aplicação do modelo transaccional à situação da criança maltratada requer que se considerem factores de risco específicos. Assim, Cicchetti e Rizley (1981) classificaram os factores de risco em duas dimensōes: tipo de influência (factores potencializadores, que aumentam a probabilidade de mau trato, e factores compensatórios, que diminuem o risco de mau trato), e influência temporal (factores de ordem passageira ou flutuante ou condições e atributos mais permanentes e constantes).

Assim, os factores de cada um dos quatro níveis ecológicos descritos por Belsky $(1980 ; 1993)$ podem ser avaliados como factores potencializadores ou compensatórios de risco, de natureza transitória ou crónica, influenciando a probabilidade do mau trato e negligência familiar às crianças. A integração destes dois modelos organizacionais define um conjunto completo de domínios e factores característicos que conduziram ao modelo ecológico-transacional, modelo que tem orientado a investigação mais actual sobre o desenvolvimento de práticas parentais abusivas (Cicchetti \& Lynch, 1993).

Embora este artigo não assuma integralmente as características de qualquer 
um destes modelos, as variáveis incluídas nos diferentes sistemas que iremos estudar serão analisadas tendo em consideração a perspectiva teórica e a estrutura destes modelos, que defendem a importância relativa de variáveis proximais (contexto de desenvolvimento e familiar), em contraste com o peso de variáveis distais (contexto social e cultural). Consequentemente, a revisão de literatura específica relativa aos factores abordados e a organização das variáveis serão guiadas por investigação a eles associada.

\section{Factores socioecológicos do mau trato e da negligência}

\section{Contexto de desenvolvimento: características das crianças}

A perspectiva de que a criança exerce efeitos no educador vem alterar a velha ideia de que são somente os factores parentais que são responsáveis pelo tipo de interacção pais-filhos, sublinhando-se uma relação bidireccional em que se enfatiza o papel do próprio comportamento da criança, e de outras suas características, na forma como se desenvolvem as relações pais-criança.

É evidência disso a existência abundante de literatura que nos últimos 15-20 anos tenta ilustrar as características da criança que influenciam o comportamento do educador. A este propósito, Belsky (1995) refere que alguns resultados de investigação reflectem mais os efeitos da criança nos pais do que os efeitos do estilo parental no funcionamento da criança. Ao nivel das populações de mau trato, esta relação tem sido evidenciada em algumas investigações. Algumas áreas que têm sido abordadas na literatura epidemiológica sobre maus tratos dizem respeito aos efeitos de variáveis sociodemográficas, tais como o sexo (Zigler \& Hall, 1989) e a idade (Belsky, 1995; van den Boom \& Hoekbma, 1994; Zigler \& Hall, 1989), assim como variáveis relativas ao seu desenvolvimento, como a saúde (Zigler \& Hall, 1989) e o aproveitamento escolar das crianças (Belsky, 1980, 1995; van den Boom \& Hoekbma, 1994).

\section{Sexo e idade das crianças}

Relativamente ao sexo, os resultados relativos à incidência de maus tratos físicos em rapazes e raparigas não mostram diferenças entre os sexos na infância. No entanto, na adolescência, os rapazes são alvo de mais abuso físico do que as raparigas e as raparigas são mais sinalizadas do que os rapazes, sobretudo no que diz respeito ao abuso sexual (Almeida, André \& Almeida, 1995; Powers \& Eckenrode, 1988; Wolfe \& McGee, 1994).

Existem alguns dados na literatura que indicam que as crianças maltratadas - ou pelo menos as crianças fisicamente maltratadas e negligenciadas — não estão 
igualmente distribuídas pelos diferentes períodos de desenvolvimento (Zigler \& Hall, 1989; Wolfe \& McGee, 1994). Nos anos 80, quer nos Estados Unidos (Powers \& Eckenrode, 1988), quer em Inglaterra (Creighton, 1985), o número de sinalizações declinava com a idade das crianças. As crianças mais novas parecem ter maior probabilidade de experienciarem mau trato e negligência, não só porque passam mais tempo e são física e psicologicamente mais dependentes dos pais, como porque são mais vulneráveis fisicamente (Belsky, 1993). No entanto, as estatísticas recentes, quer de estudos portugueses (Almeida et al., 1995; Canha, 2000), quer de outros países (Trickett \& Weinstein, 1991), revelam um número cada vez mais elevado de crianças maltratadas com idades superiores a 6-7 anos, e mesmo de adolescentes, o que parece significar, não só que o problema se torna mais visível pela sua inserção em instituições públicas, como que ele é agora mais reconhecido nos adolescentes e, portanto, mais referenciado.

\section{Saúde e aproveitamento escolar}

A relação da prematuridade e do baixo peso à nascença com o mau trato, sugerida desde o início dos estudos sobre os factores etiológicos destas situações (Klein \& Stern, 1971; Frodi, 1981) tem fomentado muita investigação cujos resultados parecem inconsistentes (Starr, 1982; Kotelchuck, 1982). A mesma inconsistência é evidente quando a atenção é focalizada nos problemas peri e neo-natais, deficiência (Starr, 1988) e saúde física em geral (Hawkins \& Duncan, 1985). Esta inconsistência nos resultados não deverá, contudo, ser interpretada como se tais factores não fossem importantes na explicação do mau trato e negligência; sugere, pelo contrário, que eles devem é ser considerados tendo em conta as características dos pais. É o caso de uma investigação desenvolvida por Sherrod, O'Connor e Altemeier (1984), em que as dificuldades de saúde precedem a ocorrência do mau trato, quando se tem em consideração o papel interactivo destes factores no processo transaccional entre pais e criança num contexto familiar e comunitário (Belsky, 1993).

A literatura refere ainda que as crianças maltratadas apresentam problemas de desenvolvimento e integração escolar quando comparadas com grupos de controlo, tanto nos diferentes tipos de mau trato e de negligência como na sua intensidade (Knutson, 1995). Um estudo longitudinal sobre os antecedentes e as consequências do mau trato, desenvolvido por Pianta, Egeland e Erickson em 1989, avalia, entre outras áreas, a adaptação escolar das crianças no fim do primeiro ano de escolaridade. Os professores referiram que as crianças fisicamente maltratadas, não só tinham um rendimento escolar mais baixo nas tarefas cognitivas e de desempenho, como cerca de metade das crianças foram referenciadas para os serviços de intervenção especial ou foram retidas no fim do ano. Contudo, foram as crianças negligenciadas aquelas que apresentaram os resultados mais baixos nas mesmas variáveis relativas à adaptação escolar, e cerca de $65 \%$ destas crianças foram referenciadas aos serviços de intervenção especial.

Num outro estudo, Eckenrode, Laird e Doris (1993) examinaram os 
resultados académicos de 420 crianças maltratadas fisicamente, negligenciadas ou com abuso sexual, que frequentavam o ensino público, comparando-as com um grupo de crianças não maltratadas emparelhadas através de variáveis sociodemográficas. Os resultados mostraram que as crianças maltratadas tinham um desempenho inferior na matemática e na leitura, recebiam notas mais baixas (C e D), e repetiam duas vezes e meia mais do que as não maltratadas. Os resultados corroboram os obtidos pelos autores descritos em cima, nomeadamente que as crianças negligenciadas são aquelas que apresentam os piores resultados.

\section{Contexto familiar: fontes de stress e de suporte}

Belsky e Vondra (1989) e Rutter (1989) sugerem que os pais abusivos pertencem a famílias com múltiplos problemas que envolvem uma grande disfunção. Factores específicos, tais como a estrutura familiar (Belsky, 1993; Zigler e Hall, 1989), a dinâmica de relações familiares (relação conjugal, organização familiar) (Almeida et al., 1995; Belsky, 1993; Cicchetti \& Lynch, 1993; Howes \& Cicchetti, 1993), e os factores de stress familiar, integram algumas das áreas estudadas, entre um número bem substanciado de resultados de investigação, que indicam que o micro-sistema destas famílias é caracterizado por estruturas e acontecimentos de stress bem diferentes dos grupos de controlo.

Como o demonstra a revisão de literatura de Jaffe, Wolfe e Wilson (1990), até hé pouco tempo as fontes familiares relacionadas com o abuso eram muitas vezes consideradas somente em termos das interacções pais-filhos, não sendo examinados os efeitos do sistema familiar no seu conjunto. Embora as interacções pais-criança sejam. no quadro do micro-sistema familiar, o subsistema mais determinante e com mais impacto no desenvolvimento da criança, a análise isolada destas interacções conduz $\hat{c}$ uma visão limitada e muito simplificada da influência familiar nos processos de educação parental. Por exemplo, o comportamento de ambos os pais e da criança nas interaç̧ões pais-filhos parece ser influenciado pela qualidade/conflito marital, assirr como por outros acontecimentos e relações familiares (Cummings, 1997).

\section{Estrutura familiar e agente do mau trato e negligência}

Também a estrutura familiar e a relação entre o perpetrador do mau trato e a criança podem influenciar o significado que o mau trato tem para esta, e assim ter consequências em função da interpretação que ela dá ao episódio (Mainly, Cicchetti \& Barnett, 1994). Se o perpetrador é uma figura parental primária, espera-se que c mau trato tenha um efeito mais profundo na criança do que se o perpetrador é alguém menos conhecido, como um familiar mais distante ou mesmo um elementc estranho à família (Mainly et al., 1994). Neste sentido, Belsky (1993) refere a importância das estruturas familiares em que coabitam substitutos parentais como padrastos/madrastas, famílias alargadas e famílias de substituição, sejam estas biológicas ou não. 


\section{Relação familiar, saúde e consumos excessivos}

Sendo, em geral, as interacções familiares nas famílias maltratantes muito pouco apoiantes (Cicchetti \& Howes, 1991), o conflito é um dos aspectos mais salientes do funcionamento familiar nestas famílias, referindo Crittenden (1985) a sua saliência, sobretudo nos pais que maltratam os filhos. Também Straus, Gelles e Steinmetz (1980), Rosenbaum e O'Leary (1981) e, em Portugal, Almeida e colegas (1995), referem uma associação entre violência conjugal e mau trato aos filhos. Desta forma, as crianças maltratadas não só observam violência na família como elas próprias a experienciam directamente (Rosenberg, 1987).

Outra fonte familiar de stress diz respeito a problemas de saúde e consumos de substâncias tóxicas (álcool e droga). Embora historicamente seja sugerido que o mau trato e o abuso de substâncias tóxicas estão relacionados, muitos investigadores têm referido a falta de estudos minimamente controlados metodologicamente que suportem esta relação (Leonard \& Jacob, 1988). Contudo, Kellehr, Chaffin, Hollenberg e Ficher (1994), através de uma amostra probabilística retirada de uma população comunitária, com comparação de sujeitos emparelhados demograficamente e controlo de variáveis espúrias, encontra a esperada relação entre mau trato e consumos de álcool e/ou drogas: $40 \%$ dos adultos com comportamentos abusivos consumiam em excesso, sendo as percentagens ainda mais elevadas nas situaçōes de negligência. Os autores referem ainda que a contribuição deste tipo de factores para a predição do mau trato e da negligência se mantém significativa, mesmo controlando variáveis como a depressão, a dimensão do agregado, perturbaçōes da personalidade e suporte social. No estudo realizado em Portugal com 224 situações de mau trato e negligência, cerca de $26 \%$ e $32 \%$ dos grupos domésticos apresentavam problemas de toxicodependência e de alcoolismo, respectivamente (Almeida et al., 1995).

\section{Contexto social: fontes de stress e de suporte}

Embora a educação parental incorpore a relação pais-criança, e por isso represente um tipo específico de relação social com características particulares, ela faz parte de um conjunto mais alargado de relações sociais (exo e macro-sistema).

Neste sentido, os estudos de matriz ecológica têm em consideração um conjunto de relações sociais que envolve amigos, vizinhos, colegas de trabalho e família mais alargada (eco-sistema específico) (Rutter, 1989). Um dos domínios que tem assumido maior importância na literatura sobre mau trato e negligência a este nível de análise diz respeito, quer à área de stress de vida provocada por factores ambientais e sociais e/ ou circunstâncias de vida causadores de stress, como o desemprego e problemas de trabalho (Steinberg, Catalano, \& Dooley, 1981), quer ainda aos factores mediadores de stress, como as redes de suporte social e institucional (Belsky, 1995; Belsky \& Vondra, 1989; Cicchetti, 1989; Garbarino, Guttmann \& Seeley, 1986; Rutter, 1987, 1989; Wolfe, 1981, 1991). 
Belsky e Vondra (1989) sugerem que, sendo a relação conjugal a principal fonte de suporte parental, as relações interpessoais entre os pais da criança e amigos, familiares e vizinhos e os técnicos e serviços comunitários funcionam como o segundo sistema de suporte mais importante. Segundo Garbarino e colaboradores (1986), a variável do meio que se constitui como um factor de compensação do sistema familiar em relação aos efeitos negativos das condições de vida precárias, tais como o desemprego, é a qualidade das relações dos sujeitos com a rede social formal e informal. Dados de investigação obtidos em diferentes grupos culturais parecem sugerir também que as mães socialmente isoladas, que não partilham as suas responsabilidades educacionais, se tornam mais rejeitantes dos filhos (Rutter, 1989). Estes resultados são consistentes com o facto de os pais que abusam e negligenciam as crianças serem mais isolados socialmente (Belsky, 1993), embora Crittenden (1985) sugira que o isolamento social é, sobretudo, uma característica dos pais negligentes.

\section{Contexto cultural}

A este nível, e segundo Rutter (1989), a relação parental deve ainda ser vista como uma relação que faz parte de um contexto social mais vasto, podendo ser afectada por factores do meio social e cultural, onde se analisam factores como a pertença a grupos e culturas diferentes e a inserção parental em contextos socioecológicos mais alargados (classe social, grupo étnico, cultura).

Por exemplo, Spearly, \& Lauderdale (1983) referem que a frequência de casos de negligência (mas não de abuso físico) é superior em famílias com rendimento económico baixo e que o abuso é superior nas zonas geográficas em que uma percentagem elevada de famílias é apoiada pela segurança social. Outros autores (e.g. Dubowitz, Hampton, Bithoney e Newberger, 1987; Zuravin \& Grief, 1989) confirmam estes resultados para os dois tipos de abuso. Saliente-se ainda que, embora o mau trato e a negligência apareçam fortemente associados aos contextos de pobreza (Almeida et al., 1995), um número considerável de crianças de níveis socioeconómicos desfavorecidos não é maltratada, e as situações de maus tratos estão representadas em todos os estratos socioeconómicos (Almeida et al., 1995).

No que se refere à dimensão étnica, as famílias de grupos minoritários, nos Estados Unidos, são muito mais referenciadas por mau trato do que as famílias euro-americanas. Contudo, quando o nível socioeconómico é controlado, parece não haver diferenças entre esses grupos (Jones \& McCurdy, 1992), embora existam razões para acreditar que os grupos étnicos diferem nos seus valores, práticas e expectativas em relação às crianças (Baldwin, Baldwin, \& Cole, 1990). 


\section{Método}

\section{Descrição das variáveis}

O mau trato e a negligência - variável dependente no estudo - foram avaliados através de um questionário construído e validado anteriormente com uma amostra de 545 crianças com idades compreendidas entre 2 meses e 15 anos (Calheiros, 1998). O questionário, após realização de uma análise factorial em componentes principais, com rotação ortogonal dos eixos, integra doze questões relativas aos comportamentos / situações de abuso e avalia três dimensões - mau trato psicológico, negligência física e mau trato físico. Cada questão é composta por três indicadores, cada um dos quais pode ser assinalado como estando "presente" ou "ausente". Cada questão deve ser cotada numa escala de 4 pontos (1, na situação de todos os indicadores ausentes, e 2, 3 ou 4, consoante o número de indicadores presentes for, respectivamente, 1,2 ou 3).

A primeira dimensão, denominada Mau Trato Psicológico, responsável por $21,6 \%$ da variância total $(58,8 \%)$ e com um alfa de Cronbach de 0,76 , é definida por falta de supervisão na área educativa e social e falta de reconhecimento e resposta às necessidades emocionais/relacionais e intelectuais das crianças. Trata-se de uma dimensão que diz respeito à inexistência de controlo da vida escolar e diária das crianças, em que os pais reforçam o desvio, impedem experiências sociais normais e veiculam um modelo social antinormativo para os filhos. Em síntese, este factor reúne um conjunto de actos e de omissões parentais que não favorece o desenvolvimento da criança aos níveis emocional, intelectual e social.

A segunda dimensão, denominada Negligência Física, responsável por $13,3 \%$ da variância, apresenta um alfa de Cronbach de 0,70 , e é definida por falta de supervisão nos cuidados físicos diários e falta de provisão nas áreas da saúde, acompanhamento médico, alimentação, vestuário e higiene, que colocam a criança em perigo ou em que já se observa dano físico aos níveis da saúde e do desenvolvimento físico e psicomotor.

A terceira dimensão, Mau Trato Físico, agrupa o conjunto de actos parentais fisicamente violentos como bater, sacudir e empurrar as crianças, assim como o uso de métodos de educação coercivos. A este tipo de mau trato, físico na sua natureza e nas suas consequências, agregam-se interacçōes verbalmente violentas e ofensivas para a criança. Responsável por $10,6 \%$ da variância, este factor apresenta um alfa de Cronbach de 0,75.

Com o objectivo de caracterizar os factores potencialmente associados à variabilidade destas dimensões de mau trato e de negligência - as variáveis independentes do estudo - utilizou-se um questionário que integrava as variáveis socioecológicas mais relevantes da literatura revista, agrupadas nos seguintes níveis de contexto:

- Contexto de desenvolvimento infantil neste nível consideraram-se as variáveis sexo, idade da criança, saúde (presença/ausência de doença crónica, 
deficiência física e atraso/deficiência mental) e situação escolar (aproveitamento durante o ano lectivo corrente: escala de $1=$ muito mau a $4=b o m$ ).

- Contexto familiar neste nível foram incluídas variáveis relativas ao cenário familiar em que a criança se desenvolve: tipo de família (família biológica, família alargada e outras pessoas - amas, internato, colocação familiar e adopção), agente do mau trato e/ou da negligência (pais vs. outro familiar ou outra pessoa) e as circunstâncias de vida familiar ou factores de stress. Relativamente ao estudo dos factores de stress familiar, foram criadas áreas específicas de stress compostas a partir das questões originais: saúde (presença/ausência de doença crónica, deficiência física e atraso/deficiência mental nos elementos da família que nāo as crianças alvo), consumos excessivos (álcool e droga) e relação familiar (presença/ausência de violência/agressividade familiar e mau entendimento familiar). Estas variáveis foram criadas a partir da presença ou ausência de cada indicador original em pelo menos um dos elementos do agregado familiar.

- Contexto social neste nível foram enquadradas variáveis da comunidade, enquanto factores específicos de stress social: trabalho (presença/ausência de desemprego e reforma) e relaçōes com a comunidade (presença/ausência de problemas nas relações com os vizinhos e discriminação da família pela comunidade). Foi ainda analisado o indice geral de factores de stress familiar e social (ausência de factores/presença de 1,2, 3 ou 4 factores de stress) e o suporte social. Este foi definido na sua vertente institucional e foi avaliado tendo em consideração os recursos institucionais ou serviços disponíveis na comunidade a que a família tinha recorrido. Desta forma, foram seleccionados sete recursos de apoio às famílias que existem nas comunidades de que a amostra foi extraída, cujo acesso é gratuito ou sem grandes custos materiais. $O$ índice de suporte social variou entre 1 e 3 instituições.

- Contexto cultural este nível de contexto integrou factores da envolvente cultural, incluindo variáveis como a classe social (nível socioeconómico baixo/nível socioeconómico médio) e a etnia (lusa, africana e cigana).

\section{Procedimento e caracteristicas da amostra}

As investigações em que são os pais ou outros elementos da família a fonte de avaliação do mau trato e da negligência, assim como de factores de natureza socioecológica a eles associados, têm conduzido a resultados cuja validade é questionável (Knutson, 1995). Assim, seguindo o exemplo de outros investigadores (e. g., Reidy, 1977; Salzinger, Kaplan, Pelcovitz, Samit, \& Krieger, 1984), neste estudo a recolha de dados é realizada com os técnicos, com base em avaliações e observações do contexto familiar, sendo os pais / adultos substitutos e as crianças os sujeitos alvo.

Os questionários foram preenchidos pelos professores que acompanham directamente estàs crianças. As crianças alvo ( $\mathrm{N}=379)$ têm idades compreendidas entre os 6 e os 15 anos e frequentam escolas públicas locais de $1 .^{\circ}$ ciclo, inseridas na sua comunidade de residência, através das quais foram referenciadas para efeitos 
de investigação, independentemente da questão directa de eventual mau trato e negligência parental, e apenas como apresentando "dificuldades na relação parental". As crianças apresentam uma média etária de 8,8 anos e desvio-padrão de 2,47.

Relativamente ao sexo da criança alvo dos maus tratos, $63,5 \%$ são do sexo masculino ( 240 crianças) e $36,5 \%$ são do sexo feminino (138 crianças), existindo na amostra uma frequência bastante superior de crianças do sexo masculino $(p=0,000)$.

\section{Apresentação e discussão dos resultados}

A apresentação dos resultados está organizada de acordo com o objectivo principal deste trabalho, que é estudar a variabilidade do mau trato e da negligência, tendo em consideração variáveis dos diferentes níveis de análise já definidos na revisão de literatura, consoante proposta de Belsky (1980; 1993) e Cicchetti e Lynch (1993).

\section{Mau trato e negligência}

Como já foi referido anteriormente, no estudo de validação do questionário de avaliação das práticas parentais abusivas (Calheiros, 1998) foram encontradas três dimensões destas práticas, denominadas mau trato psicológico, negligência física e mau trato físico. A distribuição destas três dimensões - construídas a partir da média simples dos itens que as integravam - apresenta-se no quadro1. Este permite perceber que o mau trato psicológico não só prevalece mais do que outras formas de mau trato (McGee \& Wolfe, 1991), como é claramente mais observado do que a própria negligência física.

Quadro 1 Estatistica descritiva das dimensões do mau trato e da negligência

\begin{tabular}{l|ccccc}
\hline & $\mathrm{N}$ & Média & Desvio-padrăo & Mínimo & Máximo \\
\hline Mau trato psicológico & 379 & 2,38 & 0,84 & 1 & 4 \\
Negligência física & 379 & 1,66 & 0,56 & 1 & 3,60 \\
Mau trato físico & 379 & 1,27 & 0,51 & 1 & 3,67 \\
\hline
\end{tabular}

Contexto de desenvolvimento: variáveis relativas à criança

Idade e sexo

Como mostra o quadro 2, a ANOVA identificou apenas um efeito principal da variável idade em relação ao mau trato psicológico, nenhum efeito principal da 
Quadro 2 Efeitos do sexo e da idade das crianças nas práticas parentais abusivas (valores de $\mathrm{F}$ e niveis de significância)

\begin{tabular}{l|ccc}
\hline & \multicolumn{3}{c}{ Factores } \\
\cline { 2 - 4 } & Mau trato psicológico & Negligência física & Mau trato físico \\
\hline Idade & $18,99\left(^{* *}\right)$ & 0,633 & 1,13 \\
Sexo & 0,000 & 1,55 & 0,062 \\
IdadexSexo & 0,286 & 1,02 & 0,825 \\
\hline
\end{tabular}

Nota: (") $p<0,05 ;(* *) p<0,01$.

Quadro 3 Médias das dimensões segundo a idade e sexo das crianças

\begin{tabular}{l|cc|cc}
\hline \multirow{2}{*}{ Factores } & \multicolumn{2}{|c|}{ Idade das crianças } & \multicolumn{2}{c}{ Sexo } \\
\cline { 2 - 5 } & $6-10$ anos & $11-15$ anos & Feminino & Masculino \\
\hline Mau trato psicológico & $2,26 a$ & $2,73 b$ & 2,38 & 2,38 \\
Negligência física & 1,66 & 1,69 & 1,69 & 1,64 \\
Mau trato fisico & 1,26 & 1,31 & 1,24 & 1,29 \\
$N$ & 283 & 93 & 138 & 238 \\
\hline
\end{tabular}

variável sexo e nenhuma interacção entre estas duas variáveis. Assim, como se observa no quadro 3, as médias do mau trato psicológico mostram ser o grupo dos mais velhos - pré-adolescentes e adolescentes - aquele que apresenta as médias mais elevadas $(M=2,73)$ quando comparado com os seus pares cujas idades variam entre os 6 e 10 anos $(M=2,26)$.

Saúde e aproveitamento escolar das crianças

Quando tomámos o subsistema do desenvolvimento da criança, que integra a saúde e o aproveitamento escolar como variáveis independentes, observou-se: em

Quadro 4 Efeitos do aproveitamento escolar e da saúde das crianças nas práticas parentais abusivas (valores de $\mathrm{F}$ e niveis de significância)

\begin{tabular}{l|ccc}
\hline & \multicolumn{3}{|c}{ Factores } \\
\cline { 2 - 4 } & Mau trato psicológico & Negligência física & Mau trato físico \\
\hline Aproveitamento & $3,03\left({ }^{*}\right)$ & 1,13 & $3,58\left(^{*}\right)$ \\
Saúde & 0,029 & 0,275 & 0,245 \\
Aprov.xSaúde & 1,19 & $2,83\left(^{*}\right)$ & $3,74\left(^{*}\right)$ \\
\hline
\end{tabular}

Nota: (*) $p<0,05$. 
Quadro 5 Médias das dimensōes segundo o aproveitamento escolar e a saúde das crianças

\begin{tabular}{l|cccc|cc}
\hline \multirow{2}{*}{ Factores } & \multicolumn{4}{|c|}{ Aproveitamento } & \multicolumn{2}{c}{ Saúde } \\
\cline { 2 - 7 } & M. mau & Mau & Razoável & Bom & Sem doença & Com doença \\
\hline Mau trato psicológico & $2,95 \mathrm{a}$ & $2,44 \mathrm{~b}$ & $2,20 \mathrm{~b}$ & $2,27 \mathrm{~b}$ & 2,38 & 2,18 \\
Negligència física & 1,72 & 1,72 & 1,60 & 1,65 & 1,66 & 1,78 \\
Mau Trato físico & 1,21 & 1,27 & 1,21 & 1,35 & 1,24 & 1,38 \\
N & 28 & 156 & 150 & 28 & 337 & 25 \\
\hline
\end{tabular}

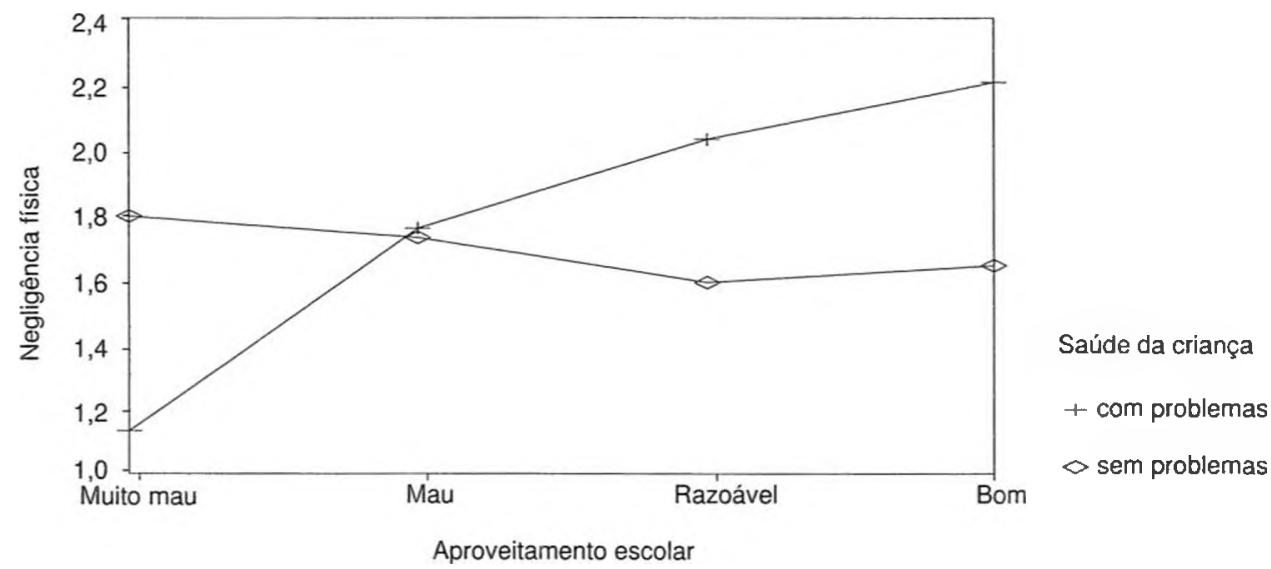

Figura 1 Efeito de interaç̧āo do aproveitamento e saúde sobre a negligència física

relação ao mau trato psicológico, um efeito principal da variável aproveitamento; em relação à negligência física, apenas uma interacção entre o aproveitamento escolar e a saúde; e em relaçāo ao mau trato físico, um efeito principal do aproveitamento escolar, secundado por um efeito de interacção desta e da saúde (quadro 4).

Como se pode observar no quadro 5, estes efeitos significam, em relação ao mau trato psicológico, que esta área do mau trato é máxima quando o aproveitamento escolar é muito mau $(M=2,95)$, sendo esta situação significativamente diferente dos três restantes níveis de aproveitamento $(\mathrm{F}=3,03 ; \mathrm{p}<0,05)$.

No que respeita ao efeito de interacçāo das duas variáveis (aproveitamento $\mathrm{e}$ saúde) sobre a dimensão negligência física $(F(3,362)=2,83 ; p(0,05)$ (figura 1$)$, as crianças com níveis muito baixos de aproveitamento e sem problemas de saúde apresentam uma média mais elevada $(M=1,79)$ do que as crianças com o mesmo rendimento académico mas com problemas de saúde $(M=1,13),(t(26)=4,39$; $\mathrm{p}<0,000)$. O inverso ocorre quando as crianças apresentam um desempenho escolar considerado razoável ou bom. Neste caso as crianças com problemas de saúde 


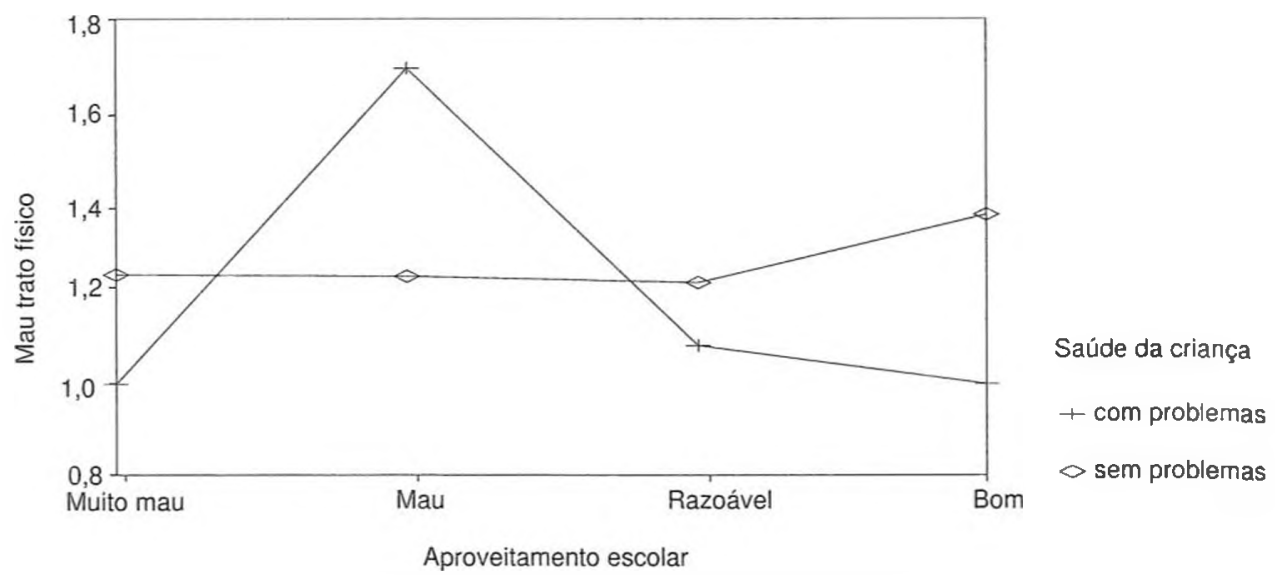

Figura 2 Efeito de interacção do aproveitamento e da saúde sobre o mau trato fisico

apresentam médias de aproveitamento superiores $(M=2,15)$ às crianças sem problemas $(M=1,60),(t(148)=2,36 ; p<0,02)$.

Nas situações de mau trato físico, o efeito de interacção $(F(3,362)=3,74$; $\mathrm{p}<0,05)$ das variáveis aproveitamento e saúde especifica o sentido do efeito principal da primeira variável, sugerindo que ela se deve ao facto de que, enquanto nas crianças sem problemas de saúde o mau trato físico é baixo e invariante em relação ao aproveitamento escolar, nas crianças com problemas de saúde, é quando o aproveitamento é mau que o mau trato físico é máximo $(M=1,69)$ e diferente das restantes condições de aproveitamento $(F=2,95 ; \mathrm{p}<0,05)$.

\section{Contexto familiar: fontes de stress e suporte familiar}

Tipo de familia e agentes dos maus tratos e da negligência

As análises de variância efectuadas com o tipo de família e o tipo de agente (quadro 6) indicam um efeito principal da variável tipo de família nas três dimensões das práticas abusivas e nenhum efeito principal do agente ou perpetrador destas práticas nem de interacção entre as duas variáveis.

Ou seja, as famílias cujos pais estão presentes $(M=2,44)$ ou que foram substituídos por outros familiares $(M=2,48)$, quando comparadas com as famílias de substituição/outras pessoas $(M=1,33)$ são aquelas que manifestam atitudes mais graves ao nível do mau trato psicológico $(\mathrm{F}(2,336)=6,42 ; \mathrm{p}<0,005)$ isto é, nos aspectos relacionados com a relação, desenvolvimento social e cognitivo.

Relativamente à negligência física, ou seja, ao acompanhamento dos aspectos 
Quadro 6 Efeitos do tipo de familia e agente do mau trato e negligência nas práticas parentais abusivas (valores de $\mathrm{F}$ e niveis de significância)

\begin{tabular}{l|ccc}
\hline & \multicolumn{3}{c}{ Factores } \\
\cline { 2 - 4 } & Mau trato psicológico & Negligencia fisica & Mau trato físico \\
\hline Tipo de familia & $6,42\left(^{* *}\right)$ & $4,07\left(^{*}\right)$ & $3,51\left(^{*}\right)$ \\
Agente & 0,966 & 0,407 & 0,423 \\
FamiliaxAgente & 2,15 & 0,423 & 1,27 \\
\hline
\end{tabular}

Nota: (") $p<0,05$; (**) $p<0,01$.

Quadro 7 Médias dos factores segundo o tipo de familia e agentes do mau trato e negligência

\begin{tabular}{l|ccc|cc}
\hline \multirow{2}{*}{ Factores } & \multicolumn{3}{|c|}{ Tipo de familia } & \multicolumn{2}{c}{ Agente } \\
\cline { 2 - 6 } & Nuclear & Familia alargada Familia substituta & Pais & Outras pessoas \\
\hline Mau trato psicológico & $2,44 \mathrm{a}$ & $2,48 \mathrm{a}$ & $1,33 \mathrm{~b}$ & 2,45 & 2,20 \\
Negligéncia fisica & $1,70 \mathrm{a}$ & $1,43 \mathrm{ab}$ & $1,22 \mathrm{~b}$ & 1,67 & 1,52 \\
Mau trato fisico & 1,30 & 1,15 & 1,33 & 1,27 & 1,33 \\
$\mathrm{~N}$ & 286 & 41 & 15 & 299 & 43 \\
\hline
\end{tabular}

básicos de saúde e higiene, ela é de novo mais elevada nas famílias nucleares $(M=1,70)$ e alargadas $(M=1,43)$, distanciando-se significativamente da forma como outras pessoas cuidam das crianças que têm ao seu cuidado $(M=1,22)$ $(\mathrm{F}(2,336)=4,07 ; \mathrm{p}<0,02)$.

Em relação às práticas fisicamente violentas, embora o valor de $\mathrm{F}(2,342)=3,51$; $p<0,05$, apresente um nível de significância aceitável, os testes post hoc não revelam essa diferença entre os grupos (quadro 7).

\section{Factores de stress e suporte familiar}

\section{Relação familiar, consumos de substâncias tóxicas e saúde}

Recorde-se que os factores de stress considerados a nível do contexto familiar (micro-sistema), foram a existência de problemas de relacionamento e violência entre os diferentes elementos da família, os problemas de saúde (doenças crónicas, deficiências físicas ou mentais) e os consumos excessivos (álcool e drogas). Desta forma, em cada uma destas áreas, considerámos as famílias em que pelo menos um dos seus elementos os apresentava, constituindo assim dois grupos (famílias com e 
Quadro 8 Efeitos da relação familiar, consumos excessivos e saúde nas práticas parentais abusivas (valores de $\mathrm{F}$ e niveis de significância)

\begin{tabular}{l|ccc}
\hline & \multicolumn{3}{|c}{ Factores } \\
\cline { 2 - 4 } & Mau trato psicológico & Negligência física & Mau trato físico \\
\hline Relaçāo familiar & $4,60\left(^{*}\right)$ & 0,534 & $25,58\left(^{* * *}\right)$ \\
Consumos excessivos & $3,33(+)$ & 0,267 & 0,849 \\
Saúde & 0,225 & 0,046 & 1,35 \\
RelaçãoxConsumos & 0,025 & 0,392 & 0,171 \\
RelaçãoxSaúde & 1,43 & 2,08 & $3,26(+)$ \\
SaúdexConsumos & 0,525 & $8,14\left(^{* *}\right)$ & $4,44(* *)$ \\
Rel.xCons.xSaúde & 0,009 & 0,129 & 0,841 \\
\hline
\end{tabular}

Notas: $(+) p<0,10>0,05 ;(") p<0,05 ;(* *) p<0,01 ;\left(^{(* *)} p<0,000\right.$.

Quadro 9 Médias dos factores segundo a relaçāo familiar, consumos excessivos e saúde

\begin{tabular}{l|cccccc}
\hline \multirow{2}{*}{ Factores } & \multicolumn{2}{|c}{ Relaçāo familiar } & \multicolumn{2}{c}{ Consumos excessivos } & \multicolumn{2}{c}{ Saúde } \\
\cline { 2 - 7 } & S/problemas & C/problemas & Sim & Não & C/ problemas & S/ problemas \\
\hline Mau trato psicológico & 2,26 & 2,50 & 2,63 & 2,28 & 2,54 & 2,35 \\
Negligẽncia física & 1,71 & 1,62 & 1,75 & 1,63 & 1,71 & 1,65 \\
Mau trato físico & 1,12 & 1,41 & 1,46 & 1,19 & 1,41 & 1,23 \\
N & 184 & 195 & 109 & 270 & 74 & 305 \\
\hline
\end{tabular}

sem problemas). No quadro 8 apresentam-se os resultados obtidos nas análises de variância com estas variáveis.

Analisem-se em primeiro lugar os efeitos das três variáveis já descritas sobre o mau trato psicológico. Como se podem constatar, existe um efeito principal da variável "relaçāo familiar" e um efeito principal tangencial da variável "consu-

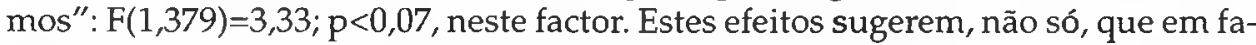
mílias com problemas de relação e violência entre adultos $(\mathrm{M}=2,50)$ e as famílias onde há problemas de álcool e drogas $(\mathrm{M}=2,63)$ - estas tendencialmente - estabelecem relações que envolvem mais mau trato psicológico com as crianças do que nas que não têm este tipo de problemas ( $M /$ relação $=2,26 ; M /$ consumos $=2,28)$.

Os resultados da análise de variância para o $2 .^{\circ}$ factor - negligência física mostram a inexistência de efeitos principais e apenas um efeito de interacção entre a saúde e o consumo excessivo de substâncias tóxicas. Essa interacçāo significa que (figura 3) as crianças cujas famílias consomem álcool ou drogas e têm problemas de saúde $(M=1,60)$ são menos negligenciadas do que as crianças que estão inseridas em famílias com consumos excessivos mas não apresentam problemas de saúde $(\mathrm{M}=1,85)(\mathrm{F}(2,236)=4,01 ; \mathrm{p}<0,05)$. Pelo contrário, as crianças cujas famílias não consomem álcool ou drogas e não tem problemas de saúde $(\mathrm{M}=1,58)$ são menos negligenciadas do que as crianças que estão inseridas em famílias sem consumos excessivos mas que apresentam problemas de saúde $(\mathrm{M}=1,80)(\mathrm{F}(2,336)=3,98 ; \mathrm{p}<0,05)$. 


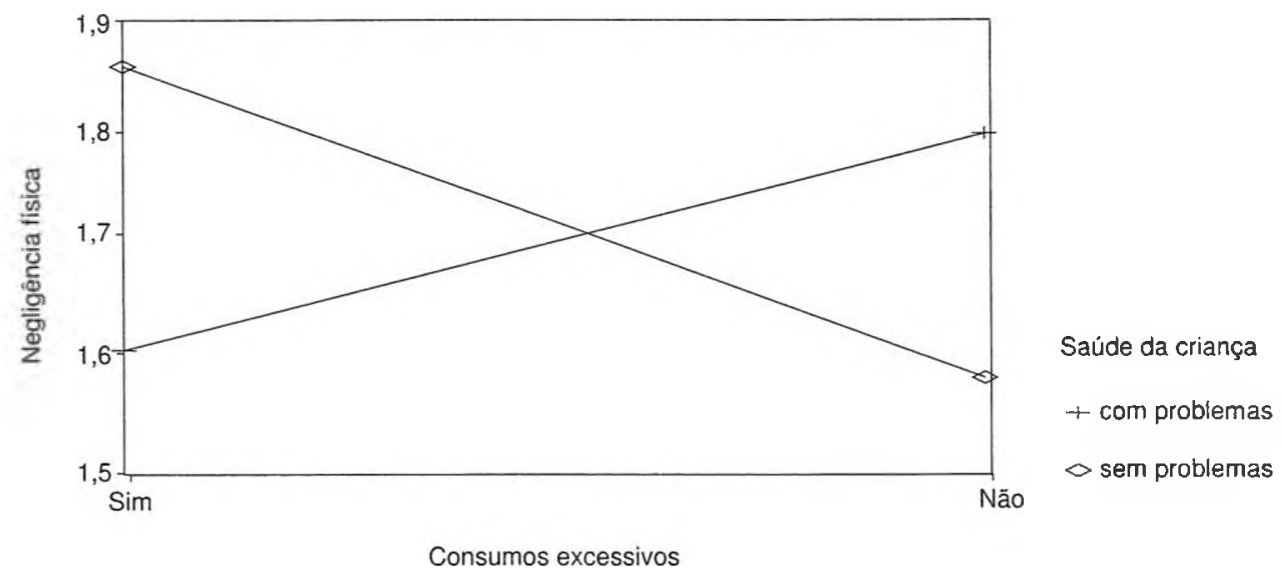

Figura 3 Interacçāo da saủde e consumos na negligência física

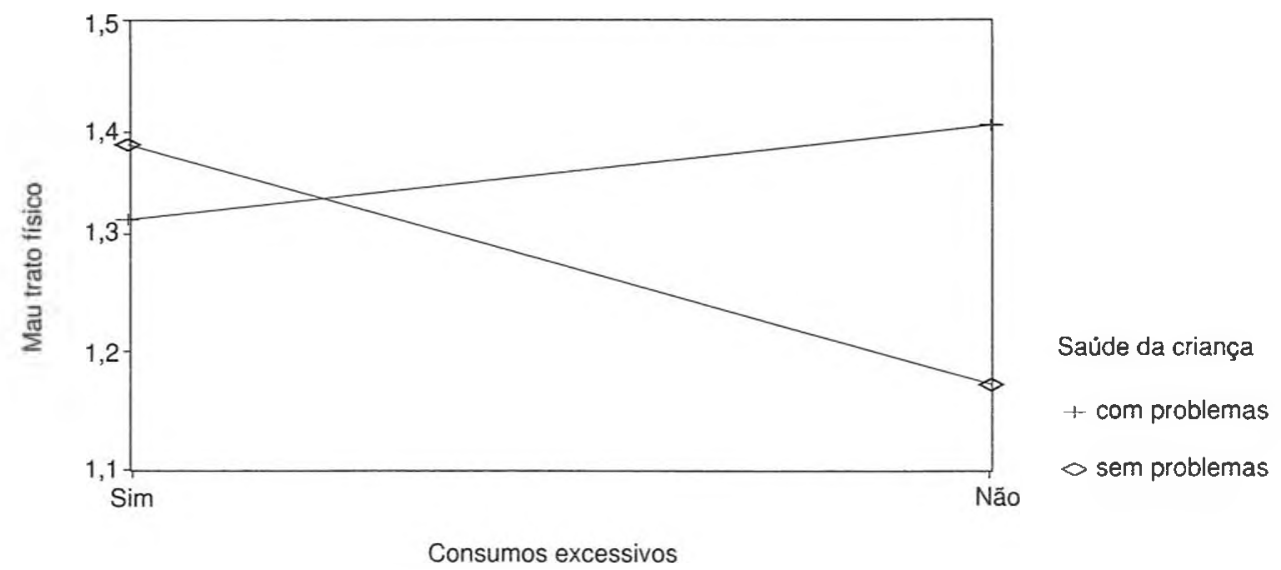

Figura 4 Interacçāo da saúde e consumos no mau trato físico

Finalmente, os resultados da análise de variância com o mau trato físico indicam um efeito principal da variável relação familiar, um efeito de interacção das variáveis "saúde" e "consumos" e ainda um efeito de interacção tangencial entre a relação familiar e a saúde familiar.

Assim, as crianças de famílias com mau relacionamento e violência entre adultos $(\mathrm{M}=1,41)$ apresentam uma gravidade de mau trato físico superior às de famílias em que estes padrões relacionais não se verificam (M=1,12).

A interacção da saúde com os consumos (figura 4) mostra que, enquanto não 
há diferenciaşa do grau de mau trato físico nas familias que consomem álcool ou droga quer as famflias apresentem $(M=1,32)$ ou ndo problemas de saúde $(M=1,39)$ $(t(107)=0,40 ; p>0,10)$, nas familias que nảo consomem, o mau trato físicamente coencivo é mais evidente nas famílias que sofrem problemas de saúde ( $\mathrm{M} / \mathrm{com}$ probl. =1.40; $\mathrm{M} /$ sem probl. $=1,17 ; t(38,96)=2,16 ; \mathrm{p}<0,04)$.

A interacçăo tangencial entre o tipo de relaçôes familiares e a saúde significa, por fim, que enquanto no quadro de relaçoes familiares sem problemas, ter problemas de saúde $(M=1,12)$ ou nåo ter problemas de saúde $(M=1,17)$ nảo interfere no grau de mau trato f́́sico $(T(48,11)=0,16, p>0,10)$, no quadro de relaçóes familiares com problemas, o mau trato físico é mais elevado quando também há problemas de saúde $(M=1,61)$ do que quando eles nảo existem $(M=1,39)(t(59,70)=2,01 ; p<0,05)$.

\section{Contexto social: fontes de "stress" e de suporte}

\section{Trabalho e relaçio na comunidade}

A primeira análise de variåncia tomou como variável dependente o mau trato psicológico e como variáveis independentes o trabalho e a relaçāo com a comunidade.

Encontrou-se apenas um efeito principal da relaçåo com a comunidade, nenhum efeito principal do trabalho e nenhuma interaç̧ão entre estas duas variáveis (quadro 10).

Assim, como mostra o quadro 11, os pais que têm problemas de relaçăo com a vizinhança e que șo discriminados no bairro onde vivem parecem estar menos implicados positivamente na educação e desenvolvimento psicossocial dos filhos $(M=2,84)$, do que aqueles que estảo inseridos de forma positiva no seu meio social $(M=2,29)$.

A segunda análise de variảncia tomou como variável dependente a negligência física, mantendo-se as mesmas variáveis indcpendentes. Os resultados obtidos apontam para a inexisténcia de qualquer tipo de efeito, quer principal quer de interacção, destas variáveis no factor (quadro 10).

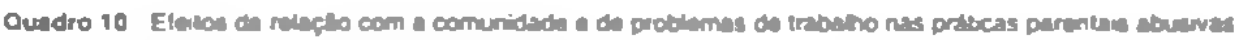

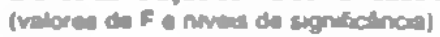

\begin{tabular}{|c|c|c|c|}
\hline & \multicolumn{3}{|c|}{ Fectores } \\
\hline & Mau inato psicotogoo & Neglghen lisuca & Mau Irato ligico \\
\hline Trabaiho & 0,099 & 2.17 & 0.292 \\
\hline Pelaça ol comunidade & $\left.22.700^{\circ}\right)$ & 1.75 & $12.001 \%$ \\
\hline Trabelhox Pelacio & 0,084 & 0.740 & 1,70 \\
\hline
\end{tabular}

Noia: (") $0<0.001$ 
Quadro 11 Médias dos factores segundo o tipo de relação com a comunidade e problemas de trabalho

\begin{tabular}{l|cc|cc}
\hline \multirow{2}{*}{ Factores } & \multicolumn{2}{|c|}{ Relaçāo com a comunidade } & \multicolumn{2}{c}{ Trabalho } \\
\cline { 2 - 5 } & C/problemas & S/problemas & C/problemas & S/problemas \\
\hline Mau trato psicológico & 2,84 & 2,29 & 2,47 & 2,34 \\
Negligência fisica & 1,78 & 1,64 & 1,78 & 1,61 \\
Mau trato fisico & 1,49 & 1,22 & 1,35 & 1,23 \\
$\mathrm{~N}$ & 67 & 312 & 121 & 258 \\
\hline
\end{tabular}

Por fim, à semelhança dos resultados encontrados para o mau trato psicológico, no mau trato físico o efeito principal da variável relação com a comunidade aponta para médias superiores de coerção física quando não existem relações integrativas com a comunidade $(\mathrm{M} / \mathrm{c} /$ problemas $=1,49 ; \mathrm{M} / \mathrm{s} /$ problemas $=1,22)$ (quadro 11).

Factores de stress e de suporte social institucional

As análises de variância com os factores de stress e suporte social como variáveis independentes sobre o mau trato psicológico, a negligência física e o mau trato físico mostraram um efeito principal da variável factores de stress nos três factores e a inexistência de efeitos principais da variável suporte social e de efeitos da interacção destas duas variáveis (quadro 12).

A ANOVA univariada dos factores de stress sobre o mau trato psicológico (Duncan, $\mathrm{p}<0,05$ ) indicou que as famílias sem factores de stress ou apenas com um $(\mathrm{M} / 1$ factor $=2,01 ; \mathrm{M} /$ nenhum factor $=2,15)$ apresentam um nível de gravidade menor de mau trato psicológico do que as famílias com 2 ou 3 factores de stress ( $M / 2$ factores $=2,42 ; M / 3$ factores $=2,49$ ) e que estas, por sua vez, são significativamente menos maltratantes do que as famílias que apresentam 4 factores de stress $(\mathrm{M}=2,78)$.

Quadro 12 Efeitos dos factores de stress e suporte social nas práticas parentais abusivas (valores de $\mathrm{F}$ e niveis de significância)

\begin{tabular}{l|ccc}
\hline & \multicolumn{3}{|c}{ Factores } \\
\cline { 2 - 4 } & Mau trato psicológico & Negligência fisica & Mau trato físico \\
\hline Factores de stress & $11,55\left(^{* *}\right)$ & $3,56\left(^{*}\right)$ & $6,77\left(^{* *}\right)$ \\
Apoio social & 2,09 & 0,426 & 2,10 \\
Stress $\times$ Apoio social & 1,54 & 1,66 & 0,240 \\
\hline
\end{tabular}

Nota: $(") p<0,01 ;\left\langle^{(*)} p<0,001\right.$. 
Quadro 13 Médias dos factores de mau trato e negligência segundo os factores de stress e apoio social

\begin{tabular}{l|ccccc|ccc}
\hline \multirow{2}{*}{ Factores } & \multicolumn{4}{|c|}{ Stress } & \multicolumn{3}{c}{ Apoio social } \\
\cline { 2 - 10 } & Nenhum & 1 & 2 & 3 & 4 & 1 & 2 & 3 \\
\hline Mau trato psicológico & $2,15 \mathrm{a}$ & $2,01 \mathrm{a}$ & $2,42 \mathrm{~b}$ & $2,49 \mathrm{~b}$ & $2,78 \mathrm{c}$ & 2,37 & 2,45 & 2,33 \\
Negligência física & $1,48 \mathrm{a}$ & $1,60 \mathrm{ab}$ & $1,69 \mathrm{bc}$ & $1,63 \mathrm{ab}$ & $1,85 \mathrm{c}$ & 1,62 & 1,68 & 1,74 \\
Mau trato fisico & $1,10 \mathrm{a}$ & $1,14 \mathrm{a}$ & $1,15 \mathrm{a}$ & $1,37 \mathrm{~b}$ & $\mathbf{1 , 5 0 \mathrm { b }}$ & 1,18 & 1,30 & 1,42 \\
$\mathrm{~N}$ & 67 & 81 & 79 & 52 & 96 & 197 & 105 & 73 \\
\hline
\end{tabular}

AANOVA univariada dos factores de stress sobre a negligência física indicou, por sua vez, que as famílias sem factores de stress $(M=1,48)$ apresentam um nível de gravidade menor de negligência do que as famílias com 2 factores de stress $(M=1,69)$, enquanto que as famílias com 3 factores de stress $(M=1,63)$ apresentam médias significativamente inferiores às famílias com 4 factores de stress $(M=1,85)$.

No mau trato físico a clivagem encontrada verifica-se, de acordo com a ANOVA univariada, entre as famílias sem factores de stress, com 1 ou $2(\mathrm{M} / \mathrm{ne}$ nhum factor=1,10;M/1 factor=1,14;M/2 factores=1,15) e as famílias que têm 3 ou 4 factores $(\mathrm{M} / 3$ factores $=1,37 ; \mathrm{M} / 4$ factores $=1,50)$.

\section{Contexto cultural}

\section{Grupo étnico e classe social}

Os resultados da análise de variância para as variáveis etnia e nível socioeconómico das famílias mostraram que a variável etnia ou a sua interacção com o nível socioeconómico não desempenham um papel significativamente diferenciador nas médias dos diferentes tipos de mau trato e negligência. Pelo contrário, na variável

Quadro 14 Efeitos da etnia e e do nivel socioeconómico nas práticas parentais abusivas (valores de $\mathrm{F}$ e niveis de significância)

\begin{tabular}{l|ccc}
\hline & \multicolumn{3}{|c}{ Factores } \\
\cline { 2 - 4 } & Mau trato psicológico & Negligência física & Mau trato físico \\
\hline Etnia & 0,124 & 1,19 & 1,31 \\
N. soceconómico & $8,42\left(^{* *}\right)$ & $19,72\left(^{* * *}\right)$ & $6,37\left({ }^{*}\right)$ \\
EtniaxN. socec. & 0,529 & 0,328 & 2,33 \\
\hline
\end{tabular}

Nota: (") $p<0,05$; ("*) $p<0,01 ;$ ("**) $p<0,001$. 
Quadro 15 Médias dos factores segundo a etnia e nivel socioeconómico

\begin{tabular}{l|ccc|cc}
\hline \multirow{2}{*}{ Factores } & \multicolumn{3}{|c|}{ Etnia } & \multicolumn{2}{c}{ Socioeconómico } \\
\cline { 2 - 6 } & Lusa & Africana & Cigana & Baixo & Médio \\
\hline Mau trato psicológico & 2,38 & 2,37 & 2,29 & 2,55 & 2,19 \\
Negligéncia física & 1,64 & 1,68 & 1,74 & 1,84 & 1,45 \\
Mau trato físico & 1,28 & 1,20 & 1,27 & 1,30 & 1,22 \\
N & 261 & 79 & 17 & 187 & 170 \\
\hline
\end{tabular}

nível socioeconómico observam-se efeitos principais sobre os três factores avaliados (quadro 14). Estes efeitos traduzem-se na diferença sistemática entre os dois grupos socioeconómicos, existindo sempre níveis mais elevados de mau trato e de negligência no grupo socioeconómico mais débil (quadro 15).

\section{Conclusões}

Com este estudo procedeu-se à avaliação do mau trato e da negligência familiar numa vasta amostra de crianças inseridas em escolas públicas e pretendeu-se contribuir para a identificação do impacto de um conjunto de variáveis psicossociais na variabilidade das práticas de mau trato e de negligência familiar.

Os problemas recenseados na literatura, sobre a inconsistência das definições, a validade questionável dos instrumentos e métodos de avaliação do mau trato e da negligência e a não inclusão dos diferentes grupos na investigação sobre os determinantes de práticas parentais abusivas sugeriram-nos a aplicação de um questionário previamente testado que servisse como medida de avaliação do mau trato e da negligência. Segundo os resultados que obtivemos - incluindo as três dimensões ortogonais anteriormente estudadas, mau trato psicológico, negligência e mau trato físico (Calheiros, 1998) - , os pais manifestam sobretudo dificuldades nas áreas educativas e sociais, não reconhecendo as necessidades emocionais/relacionais e intelectuais das crianças. São pais que não controlam a vida escolar e diária das crianças, reforçam o desvio, impedem experiências sociais normais e exercem um modelo social antinormativo com os filhos, ou seja, o mau trato psicológico aparece relativamente elevado.

O facto de se ter constituído uma amostra natural e não seleccionada a partir de populações maltratantes fez sobressair esta dimensão das práticas parentais abusivas (tipologia menos referenciada em literatura de investigação) e não o mau trato físico, área mais facilmente identificada e sinalizada pelos técnicos às instituições de protecção de menores, constituindo-se a categoria melhor documentada na literatura (Crittenden, Claussen e Sugarman, 1994; Manly et al., 1994). 
Por sua vez, o facto de também se questionar o recurso a modelos unidimensionais sobre os determinantes do mau trato e negligência e o aparecimento recente de abordagens integrativas em que se salienta a importância de múltiplas variáveis organizadas em diferentes sub-sistemas nos quatro níveis de análise - ontogénico, micro, exo e macro - sugeriram-nos uma perspectiva de análise de matriz ecológica sobre os determinantes das práticas parentais abusivas. Desta forma, foram integradas variáveis que vão desde o contexto de desenvolvimento e da interacção pais-filhos, até ao contexto social e cultural, passando pelo sistema familiar.

As conclusōes que se seguem dizem respeito ao segundo objectivo do estudo.

Vejamos então como se articularam as variáveis da criança enquanto contexto de desenvolvimento na interacção pais-filhos.

A primeira grande conclusão é que as variáveis da criança desempenham um papel importante na modulação das práticas parentais abusivas.

Assim, e embora a gravidade das práticas parentais abusivas não se relacione com o sexo da criança, pois este só parece ser importante na medida em que, proporcionalmente, o mau trato e a negligência são observados com maior frequência nos rapazes do que nas raparigas - a idade parece ser um determinante a referir sobretudo no mau trato psicológico. Os educadores parecem protelar para segundo plano a educação e controlo dos filhos mais velhos, pois não reconhecem as suas necessidades, nem dão as respostas necessárias a nível emocional, social e intelectual. Talvez porque acreditam nas capacidades de autonomia e auto-regulação nesta faixa etária, ou porque acreditam que a infância destas crianças já terminou e que já passaram à idade adulta, demitindo-se então a família do papel exercido até então. Seria, assim, interessante explorar, em futuros estudos, as crenças destes, e de outros pais sobre o decurso do desenvolvimento, a infância e o papel familiar na educação de crianças entre os 11 e os 15 anos.

As crianças menos envolvidas nas aprendizagens escolares, independentemente da sua situação de saúde, conduzem a um maior afastamento parental das suas funções educativas, quer a nível do controlo académico, quer a nível de outras áreas de desenvolvimento socioemocional dos filhos. ${ }^{2} \mathrm{O}$ u seja, face às dificuldades das crianças, os pais, em vez de investirem em mecanismos de autocorrecção do sistema, demitem-se do seu papel compensatório.

Em relação à negligência, enquanto as crianças sem problemas de saúde são invariantes em funçāo do aproveitamento, as crianças com problemas de saúde são mais negligenciadas à medida que o sen nível de aproveitamento é superior.

Também o mau trato físico é modulado pelo aproveitamento e saúde da criança. Enquanto, nas crianças sem problemas, as práticas parentais fisicamente abusivas são praticamente inexistentes e invariantes em relaçāo ao aproveitamento escolar, nas crianças com problemas de saúde é quando o aproveitamento é mau que a violência e coerção são máximas.

De seguida apresentam-se as conclusões relativas à importância das variáveis da família nos diferentes tipos de mau trato e negligência, o que conduz à segunda grande conclusão deste estudo. Ou seja, também este nível de análise parece ser revelador. Como já era de esperar, e seguindo os resultados obtidos por Almeida e colegas (1995) e Belsky (1993), entre outros, a forma como as famílias estão 
estruturadas, as suas relações e problemas são determinantes a ter em conta nas práticas parentais.

As famílias cujos pais ou outros familiares estão presentes, quando comparadas com as familias de substituição/outras pessoas, são aquelas que manifestam atitudes mais graves a nível do mau trato psicológico e da negligência física, isto é, nos aspectos relacionados com a relação, desenvolvimento social e cognitivo e condições básicas de saúde e bem-estar físico.

O facto de estes agregados (famílias de pertença e não de substituição) apresentarem os valores mais elevados nestes factores, duma forma geral, pode não indicar que as famílias naturais eduquem os filhos mais negligentemente, quer física quer psicologicamente. Mas o terceiro grupo, aquele que é composto por situações não familiares, mas institucionais, representando já uma segunda alternativa de coabitação por incapacidade ou impossibilidade dos pais biológicos e dos seus familiares educarem as crianças, apresenta, de facto, um nível inferior deste tipo de práticas educativas.

Resultado interessante, mas não surpreendente, é o obtido nas práticas fisicamente violentas, que aponta para que as famílias biológicas e as colocações institucionais ou outras revelem níveis mais graves de coerção e violência. $O$ facto de estas práticas se salientarem nestes grupos leva-nos a concluir que a violência física sobre a criança poderá estar mais associada a outras pessoas que vivem no agregado (padrasto, por exemplo) ou a núcleos familiares em que as crianças não têm qualquer tipo de relação biológica com os educadores. No entanto, se, por um lado, estes resultados confirmam outras investigações realizadas noutros países ( $c f$. em Knutson, 1995), onde se verifica que "figuras de autoridade" na família, que não os pais, têm um papel importante na vitimização do mau trato, por outro, levantam ainda a hipótese de que algumas "famílias de substituição", sendo já uma segunda alternativa para as crianças, não implicam necessariamente uma resolução positiva relativamente às situações anteriores em que estas viviam. ${ }^{3}$

No que diz respeito aos factores de stress familiar, à semelhança dos autores já referidos na revisão de literatura, os resultados apontam para que, em famílias com problemas de relação e violência entre adultos, se observem níveis mais graves de mau trato psicológico e físico (Ciccetti \& Howes, 1991; Crittenden, 1985), sendo que o consumo de álcool e drogas também influencia negativamente o mau trato psicológico (Almeida et al., 1995; Kellehr et al., 1994).

As crianças cujas famílias consomem álcool ou drogas e têm problemas de saúde são menos negligenciadas do que as crianças que estão inseridas em famílias com consumos excessivos mas que não apresentam problemas de saúde. Pelo contrário, as crianças cujas famílias não consomem álcool ou drogas e não têm problemas de saúde são menos negligenciadas do que as crianças que estão inseridas em famílias sem consumos excessivos mas que apresentam problemas de saúde.

Enquanto não há diferenciação de médias de mau trato físico nas famílias que consomem álcool ou droga, quer estas apresentem ou não problemas de saúde, nas famílias que não consomem, o mau trato fisicamente coercivo é mais evidente nas famílias que sofrem de problemas de saúde. 
Passemos agora para as variáveis do contexto social. Ao contrário dos resultados apontados por Steinberg e colegas (1981) e Belsky (1993) sobre a importância do trabalho na modulação do mau trato e da negligência, na amostra em estudo, só os pais que têm problemas de relação com a vizinhança e que são discriminados no bairro onde vivem parecem ser os menos implicados positivamente na educação e no desenvolvimento psicossocial dos filhos (mau trato psicológico) e assumirem práticas físicamente violentas. Contudo, e assim como Belsky e Vondra (1989), Cicchetti (1989) e Wolfe (1991), também nós confirmámos a hipótese de que os factores de stress, sobretudo se os tomarmos em consideração no seu conjunto, cumulativamente, condicionam de forma negativa os níveis de gravidade de mau trato $e$ negligência.

No que diz respeito aos factores de suporte familiar, a hipótese de que estes poderiam atenuar o problema do mau trato e da negligência (Bronfenbrenner, 1986) não se confirma através dos resultados alcançados. Pelo contrário, os dados obtidos na nossa amostra indicam que as crianças que beneficiam de maior apoio institucional são aquelas que apresentam niveis mais graves do problema. Dado que nem todos os suportes que foram avaliados têm respostas específicas para o problema do mau trato e da negligência, sobretudo aqueles que são mais frequentados/procurados (centros de saúde, escolas, segurança social, etc.), podemos colocar a hipótese de que o tipo de intervenção implementado por estas instituições não actue directamente na minimização do problema. Por outro lado, há que considerar que as variáveis de suporte social institucional podem ter um contributo menos relevante do que variáveis de suporte não formal, como o suporte social, familiar, etc. É nesta linha que integramos o resultado acima descrito, com as famílias socialmente isoladas a manifestarem níveis mais elevados de mau trato físico e psicológico.

Finalmente, podemos acrescentar que as variáveis de nível cultural só influenciam parcialmente as práticas parentais abusivas, pois as suas médias só são significativamente mais elevadas na situação das famílias socioeconomicamente débeis e não em função da etnia. Estes resultados parecem confirmar as hipóteses colocadas por outros autores (Dubowitz et al., 1987; Spearly \& Lauderdale, 1983), sobre a saliência do rendimento económico no mau trato e na negligência e sobre o papel indiferenciado da etnia na gravidade destas práticas parentais.

No entanto, conforme se referiu na introdução do artigo, as dificuldades de integração da literatura nesta área tornam difícil a tarefa de olhar para os resultados obtidos à luz de investigações precedentes, não só por aquelas se basearem em estudos epidemiológicos, como por se estar a comparar resultados obtidos com amostras e através de instrumentos de medida tão diversificados. Por esta razão, e dado esta investigação assumir um carácter exploratório, a replicação deste tipo de estudos torna-se necessária, de forma a poder-se estabelecer relações consistentes entre as variáveis e a generalização e comparação dos resultados. 


\section{Notas}

1 A correspondência relativa a este trabalho deve ser endereçada a Manuela Calheiros, Departamento de Psicologia Social e das Organizações, ISCTE, Av. das Forças Armadas, 1600 Lisboa (e-mail: maria.calheiros@iscte.pt)

2 Porque o nível de aproveitamento escolar pode resultar da situação de mau trato (Starr, Dietrich, Fischoff, Ceresnie \& Zweier, 1984), o papel desta variável como predictora pode ser questionado em estudos prospectivos como este.

3 Não se conhecendo os motivos porque estas crianças foram separadas dos pais, avaliámos neste estudo a situação de mau trato e negligência na família em que vivem actualmente.

\section{Referências}

Almeida, A. N., André, I. M., \& Almeida, H. N. (1995). Os maus tratos às crianças em Portugal: Relatório final - 1." fase. Lisboa: Centro de Estudos Judiciários.

Baldwin, A. L., Baldwin, C., \& Cole, R. (1990). Stress: resistant families and stress-resistant children. In J. E. Rolf, A. Masten, D. Cicchetti, K. H. Nuechterlein, \& S. Weintraud (Eds.), Risk and protective factors in the development of psychopathology. Nova Iorque: Cambridge University Press.

Belsky, J. (1980). Child maltreatment: An ecological integration. American Psychologist, 35, 320-335.

Belsky, J. (1993). The etiology of child maltreatment: A developmental-ecological analysis. Psychological Bulletin, 114, 413-434.

Belsky, J. (1995). Determinants and consequences of parenting: Illustrative findings and basic principles. In W. Hellinckx, M. Coiton \& M. Williams (Eds.), The family zuay: International perspectives on family support. Aldershot, UK: Arena.

Belsky, J., \& Vondra, J. (1989). Lessons from child abuse: The determinants of parenting. In D. Cicchetti \& V. Carlson (Eds.), Child maltreatment: Theory and research on the causes and consequences of child abuse and neglect. Nova Iorque: Cambridge University Press.

Bronfenbrenner, U. (1979). The ecology of human development. Cambridge, MA: Harvard University Press.

Bronfenbrenner, U. (1986). Ecology of the family as a context for human development research perspectives. Developmental Psychology, 22 (6), 723-742.

Canha, J., (2000). Criança maltratada: O papel de uma pessoa de referência na sua recuperaçāo - Estudo prospectivo de 5 anos. Coimbra: Quarteto Editora.

Calheiros, M., (1998). Elaboração e estudo de um questionário de avaliação de maus tratos e negligência a crianças. Revista Portuguesa de Psicologia, 33, 91-121.

Cicchetti, D. (1989). How research in child maltreatment has informed the study of child development: Perspectives from developmental psychopathology. In D. Cicchetti 
\& V. Carlson (Eds.), Child maltreatment: Theory and research on the causes and consequences of child abuse and neglect. Nova Iorque: Cambridge University Press.

Cicchetti, D., \& Howes, T. W. (1991). Development psychopathology in the context of the family: Ilustrations from the study of child maltreatment. The Canadian Journal of Behavioural Science, 23, 257-281.

Cicchetti, D., \&, Lynch, M. (1993). Toward an ecological/transactional model of comunity violence and child maltreatment: Consequences for children's development. Psychiatry, 56, 96-118.

Cicchetti, D., \& Rizley, R. (1981). Developmental perspectives on the etiology, intergerational transmissions, and sequelae of child maltreatment. Nezv Directions for Child Development, 11, 31-55.

Cicchetti, D., \& Toth, S. (1995). A developmental psychopathology perspective on child abuse and neglect. Journal of American Academy of Child and Adolescent Psychiatry, 34, 541-565.

Creighton, S. (1985). Epidemiological study of abused children and their families in the United Kingdom between 1977 and 1982. Child Abuse and Neglect, 9, 441-448.

Crittenden, P. M., (1985). Social networks, quality of parenting and child development. Child Development, 56, 1299-1313.

Crittenden, P. M., Claussen, A. H., \& Sugarman, D. B. (1994). Physical and psychological maltreatment in middle childhood and adolescence. Development and Psychopathology, 6, 145-164.

Cummings, E. M., (1997). Marital conflict, abuse, and adversity in the family and child adjustment: developmental psychopathology perspective. In D. A. Wolfe, R. J. McMahon, \& R. De V. Peters (Eds.), Child abuse: New directions in prevention and treatment across the lifespan. Nova Iorque: Sage.

Dubowitz, H., Hampton, R. L., Bithoney, W. G., \& Newberger, E. (1987). Inflicted and noinflicted injuries: Differences in child and familial characteristics. American Journal Orthopsychiatry, 57 (4), 525-535.

Eckenrode, J. Laird, M., \& Doris, J. (1993). School performance and disciplinary problems among abused and neglected children. Developmental Psychology, 29, 53-62.

Frodi, A. M., (1981). Contributions of infant characteristics to child abuse. American Journal of Mental Deficiences, 85, 341-349.

Garbarino, J., Guttmann, E., \& Seeley, J. (1986). The psychologically battered child. Nova Iorque: Joney-Bass Publishers.

Hawkins, W. E., \& Duncan, D. F. (1985). Children's illnesses as risk factors for chil abuse. Psychological Reports, 56,638

Howes, P., \& Cicchetti D. (1993). A family/relational perspective on maltreating families: parallel process across systems and social policy implications. In D. Cicchetti \& S. L. Toth (Eds.), Child abuse, child development and social policy (pp. 249-300). Norwood, NJ: Ablex.

Iverson, T. J., \& Segal, M. (1992). Social behavior of maltreated children: Exploring links to parent behavior and beliefs. In I. E. Sigel, A. V. McGillicuddy-De Lisi \& J. J. Goodnow (Eds), Parental belief systems: The psychological consequences for children. Hillsdale, NY: Lawrence Erlbaum Associates.

Jaffe, P. G., Wolfe, D. A., \& Wilson, S. K. (1990). Children of battered women. Newbury Park, CA: Sage. 
Jones, E. D., \& McCurdy, K. (1992). The links between types of maltreatment and demographic characteristics of children. Child Abuse and Neglect, 16, 201-215.

Kellehr, K., Chaffin, M., Hollenberg, J., \& Ficher, E. (1994). Alcohol and drug disorders among physically abusive and neglectful parents in a community-based sample. American Journal of Public Health, 84, 1586-1590.

Klein, M., \& Stern L. (1971). Low birth weight and the battered child syndrome. American Journal of Disabylity Child, 122, 15-18.

Knutson, J. F. (1995). Psychological characteristics of maltreated children: Putative risk factors and consequences. Annual Reviewo Psychology, 46, 401-31.

Kotelchuck, M. (1982). Child abuse and neglect: Prediction and misclassification. In R. H. Starr Jr. (Ed.), Child abuse prediction: Policy implications. Cambridge, MA: Ballinger.

Leonard, K. E., \& Jacob, T. (1988). Alcohol, alcoholism, and family violence. In V. B. Van Hasselt, R. L. Morrison, A. S. Bellack \& M. Hersen (Eds.), Handbook of family violence (pp. 383-406). Nova Iorque: Plenum.

Manly, J. T., Cicchetti, D., \& Barnett, D. (1994). The impact of subtype, frequency, chronicity, and severity of child maltreament on social competence and behavior problems. Development and Psychopathology, 6, 121-143.

McGee, R. A., \& Wolfe, D. M. (1991). Psychological maltreatment: Towards an operational definition. Development and Psychopathology, 3, 3-18.

Pianta, R., Egeland, B., \& Erickson, M. F. (1989). The antecedents of maltreatment: Results of the mother - child interaction research project. In D. Cicchetti \& V. Carlson (Eds.), Child maltreatment: Theory and research on the causes and consequences of child abuse and neglect. Nova Iorque: Cambridge University Press.

Powers, J. L., \& Eckenrode, J. (1988). The maltreatment of adolescents. Child Abuse and Neglect, 12, 189-199.

Reidy, T. J. (1977). The agressive characteristics of abused and neglected children. Journal of Clinical Psychology, 33, 1140-1145.

Rosenbaum, A. \& O'Leary, D. (1981). Marital violence: Characteristics of abusive couples. Journal of Consulting and Clinical Psychology, 49, 63-71.

Rosenberg, M. S. (1987). New directions for research on the psychologycal maltreatment of children. American Psychologist, 40, 104-106.

Rossman, B. B. R., \& Rosenberg, M. S. (1998). The multiple victimization of children: Incidence and conceptual issues. In B. B. R. Rossman \& M. S. Rosenberg (Eds.), Multiple victimization of children: Conceptual, developmental, research and treatment issues (pp. 1-6). Binghamton, NY: Haworth.

Rutter, M. (1987). Psychosocial resilience and protective mechanisms. American Journal of Orthopsychiatry, 57 (3), $316-331$

Rutter, M. (1989). Intergenerational continuities and discontinuities in serious parenting difficulties. In D. Cicchetti \& V. Carlson (Eds.), Child maltreatment: Theory and research on the causes and consequences of child abuse and neglect. Nova Iorque: Cambridge University Press.

Salzinger, S., Kaplan, S., Pelcovitz, D., Samit, C., \& Krieger, R. (1984). Parents and teacher assessment of children's behavior in child maltreating families. Child Psychiatric, $23,458-464$. 
Sameroff, A. J., \& Chandler, M. J. (1975). Reproductive risk and the continuum of caretaking casuality. In F. D. Horowitz, M. Hetherington, S. Scarr-Salapatek \& G. Sigel (Eds.), Review of child development research (vol. 4, pp. 187-243). Chicago: Univeristy of Chicago Press.

Sherrod, K. B., O'Connor, S., \& Altemeier, W. A., (1984). Child health and maltreatment. Child Development, 55, 1174-83.

Spearly, J. L., \& Lauderdale, M. (1983). Community characteristics and ethnicity in the prediction of child maltreatment rates. Child Abuse and Neglect, 7 (1), 91-105.

Starr, R. H., Jr. (1982). A research-based approach to the prediction of child abuse. In R. H. Starr, Jr. (Ed.), Child abuse prediction: Policy implications (pp. 105-134). Cambridge, MA: Ballinger.

Starr, R. H., Jr. (1988). Pre and perinatal risk and physical abuse. Journal of Reprod. Infant Psychology, 6, 125-138.

Starr, R. H., Dietrich, K. N., Fischoff, J., Ceresnie, S., \& Zweier, D. (1984). The contribution of handicapping condictions to child abuse. Top Early Child Special Education, 4, 55-69.

Steinberg, I., Catalano, R., \& Dooley, D. (1981). Economic antecedents on child abuse and neglect. Child Development, 52, 975-985.

Straus, M. A., Gelles, R. J., \& Steinmetz, S. K. (1980). Behind closed doors: Violence in the American family. Garden City, NI: Anchor Press.

Trickett, P. K., \& Weinstein, R. (1991). Physical abuse of adolescents. In R. Lerner, A. Peterson, \& J. Books-Gunn (Eds.), Encyclopedia of adolescence (Vol. II, pp. 780-784). Nova Iorque: Garland.

van den Boom, D., \& Hoekbma, J. (1994). The effect of infant irritability on mother-infant interaction. Developmental Psychology, 30, 581-590.

Wolfe, D. A. (1981). Origins of child abuse and neglect within the family. Child Abuse and Neglect, 5, 223-229.

Wolfe, D. A. (1991). Preventing physical and emotional abuse of children. Nova Iorque: The Guilford Press.

Wolfe, D. A., \& McGee, R. (1994). Dimensions of maltreatment and their relationship to adolescent adjustment. Development Psychopathology, 6, 165-181.

Zigler, E., \& Hall, W. N. (1989). Physical child abuse in America: Past, present, and future. In D. Cicchetti \& V. Carlson (Eds.), Child maltreatment: Theory and research on the causes and consequences of child abuse and neglect. Nova lorque: Cambridge University Press.

Zuravin, S. J., \& Grief, G. L. (1989). Normative and child-maltreatment AFDC mothers: Social casework: The Journal of Contemporary Social Work, 74, 76-84.

Social-ecological contexts of children maltreatment and neglect (abstract) The aim of the study is to analyse the importance of several social psychological variables on the variability of parental patterns of maltreatment and neglect with their children. The theoretical frameworks include Belsky's ecological model (1980; 1993; 1995) and Cicchetti and col. 's transactional model (Cicchetti \& Rizley, 1981; Cichetti \& Lynch, 1993) concerning the determinants of parental behaviour. 379 
children of Lisbon public schools, aged 6 to 15 , were assessed by their teachers that filled in two questionnaires. The first assessed parental abusive behaviours of physical and psychological maltreatment and physical neglect. The second assessed children and family variables concerning the ontogenical context as well as their micro-, exo-, and macro-systems. Results show the importance of children's, family's and ecological variables on parental abusive behaviours, the most salient being child's age, health and school achievement; family's structure, health, internal violence and drug consumption; social isolation or discrimination. 